\title{
The Relationship of Knowledge Level of Installation and Maintenance with the Successful Use of Soft Contact Lens in Myopia patients
}

\author{
DIDIK WAHYUDI ${ }^{1}, \mathrm{~J}^{\mathrm{DAHJONO}}{ }^{2}$, UNTUNG SUPARMAN ${ }^{3}$ \\ 1,2,3 Lecturer of DIII Refraction Optics, Faculty of Health and Medical Engineering, Widya Husada University Semarang \\ Correspondence to Didik Wahyudi, Email: didikwahyudidamarmenur812@gmail.com
}

\begin{abstract}
Background: Refractive errors have occurred in many parts of the world, including in Indonesia, with different types of abnormalities, one of which is myopia which can be corrected with glasses and spherical contact lenses. Aim: To determine the relationship between the level of knowledge of the installation and care of soft contact lenses in myopic patients.

Methods: This research method is Cross Sectional at Optik Metro, the number of samples is the total population, the research instrument is a questionnaire, the independent variable of this research is the level of knowledge while the dependent variable is the attitude and behavior of Care and Installation with Successful Use of Contact Lenses. This research has been approved by the Widya Husada STIKES Ethics Commission.

Results: The results of the study based on the number of sufferers and the distribution of refractive errors at Optik Metro from March 15-20, 2021, showed that the number of myopia patients who came was $13.0 \%$ with the type of treatment using soft contact lenses as much as $2.2 \%$. There is a relationship between knowledge and attitudes of respondents with maintenance and installation behavior with successful use of LK with a significance value of $0.000(p<0.05)$.

Conclusion: It was concluded that the toric soft contact lens installation procedure was carried out in the right way by taking into account a good fitting assessment. It is necessary to provide education to increase knowledge and education on Care and Installation of Contact Lenses for all customers.

Keywords: Knowledge, Attitude, Soft LK, Myopia
\end{abstract}

\section{INTRODUCTION}

Nowadays, the development and modernization of technology is found in various fields, including medical devices in the field of refractive disorder rehabilitation. Refraction is a refractive deviation that occurs in the eye caused by the inaccurate fall of the image on the retina, or the difference in the curvature of the cornea. With the presence of a refractive device, patients with refractive error status such as myopia, hypermetropia or astigmatism can be able to see with sharp eyesight like an emmetropic (normal) person.

The most common refractive error in Indonesia is myopia, however, astigmatism is found with different ages and causes. Myopia is a visual aberration caused by the point of focus being refracted and falling in front of the retina. Correction of refractive errors in myopia patients is to use glasses or by using contact lenses. Although most people with myopia choose to use glasses for reasons of convenience and cheap prices, but also many people with myopia choose to use contact lenses. The reasons for using contact lenses vary, such as occupational factors, high ametropia, or cosmetic considerations.

Myopia refractive fabric causes blindness, it is necessary to prevent and overcome the occurrence of high myopia. Efforts to prevent and control high myopia begin by increasing public knowledge and awareness about myopia rehabilitation and its complications. The knowledge possessed by the community boils down to practice and lifestyle, good knowledge leads to appropriate behavior in general. Individuals with visual acuity usually will not perform this action due to ignorance or negligence. This study aims to determine the relationship between the level of knowledge of the installation and the care of soft contact lenses in myopia sufferers at Optik Metro Semarang

\section{METHOD}

The method of this research is Cross Sectional because this research looks for the relationship between the level of knowledge of Care and Installation with the Successful Use of Contact Lenses in 2021 at Optik Metro. The location of this research is Optik Metro Semarang, the number of samples is the total population. The independent variable of this study is the level of knowledge while the dependent variable is the attitude and behavior of Care and Installation with the Successful Use of Contact Lenses in 2021 at Optik Metro. This research has been approved by the Widya Husada STIKES Ethics Commission.

\section{RESULTS}

Location Overview: This study is about the relationship of knowledge and attitudes with Care and Installation behavior with the successful use of contact lenses in 2021 at Optik Metro. Located on the main road of Semarang City and has several branches. The research team from Jalan Subali Raya no. 12 Krapyak Semarang is included in the West Semarang sub-district with a strategic location close to the Ahmad Yani airport in Semarang.

Characteristics of Respondents by age: In this variable age is grouped into two groups, namely under 17 years and above 17 years. Most of the respondents are 21 years old, which is $64 \%$ and the rest of the respondents are 20 years old with a percentage of $36 \%$.

Distribution of Respondents by Gender: Based on gender, $66 \%$ of respondents were male, while the remaining $34 \%$ (17 people out of 50 people) were female. 
Distribution of Respondents by Knowledge: Based on knowledge, most of the customers understand about Maintenance and Installation with the Successful Use of Contact Lenses in 2021 at Optik Metro, which is as much as $64 \%$. Only $36 \%$ who do not understand the Maintenance and Installation with the Successful Use of Contact Lenses in 2021 at Optik Metro.

Distribution of Respondents by Attitude: Distribution based on attitudes, most respondents have Care and Installation behavior with Successful Use of Contact Lenses in 2021 at Optik Metro, which is 64\% (32 out of 50) while the remaining $36 \%$ have radiation protection behavior for poor eye health

Distribution of Respondents According to Care and Fitting Behavior with Successful Use of Contact Lenses: Based on the behavior of Care and Installation Behavior with Successful Use of Contact Lenses, most of the respondents have a behavior with a positive category, namely $58 \%$ (29 out of 50 ). Meanwhile, $42 \%$ of other respondents have negative consumption behavior.

Table 7 shows that there is a relationship between the respondent's knowledge with Care and Installation Behavior with the Successful Use of Contact Lenses in 2021 , as evidenced by a significance value of 0.000 ( $p<$ $0.05)$.

Table 8 shows that there is a relationship between the respondent's attitude with Care and Installation Behavior with the Successful Use of Soft Contact Lenses at Optik Metro in 2021, as evidenced by a significance value of $0.000(p<0.05)$. During the study, the total population who came to the optical metro with the aim of correcting refractive errors or overcoming different refractive statuses.

Table 1: Distribution of Respondents by Age

\begin{tabular}{|l|c|c|}
\hline Age & $\mathbf{n}$ & $\%$ \\
\hline 20 Years & 18 & 36,0 \\
\hline 21 Years & 32 & 64,0 \\
\hline Total & 50 & 100,0 \\
\hline
\end{tabular}

Table 2: Distribution of Respondents by Gender Optical Metro Semarang in 2021

\begin{tabular}{|l|c|c|}
\hline Gander & $\mathbf{n}$ & $\%$ \\
\hline Male Female & 33 & 66,0 \\
\hline Perempuan & 17 & 34,0 \\
\hline Total & 50 & 100,0 \\
\hline
\end{tabular}

Table 4: Distribution of Respondents Based on Knowledge of Care and Installation with Successful Use of Contact Lenses in 2021 at Optik Metro.

\begin{tabular}{|l|c|c|}
\hline Knowledge & $\mathbf{n}$ & $\%$ \\
\hline Not Good & 18 & 36,0 \\
\hline Good & 32 & 64,0 \\
\hline Total & 50 & 100,0 \\
\hline
\end{tabular}

Table 5 Distribution of Respondents Based on Care and Installation Attitudes with Successful Use of Contact Lenses in 2021 at Metro Optics.

\begin{tabular}{|l|c|c|}
\hline Attitude & $\mathbf{n}$ & $\%$ \\
\hline Not Good & 18 & 36,0 \\
\hline Good & 32 & 64,0 \\
\hline Total & 50 & 100,0 \\
\hline
\end{tabular}

Table 6: Distribution of Respondents by Maintenance and Installation Behavior with Successful Use of Contact Lenses in 2021 at Metro Optics.

\begin{tabular}{|l|c|c|}
\hline $\begin{array}{l}\text { Maintenance and Installation Behavior } \\
\text { with Successful Use of Soft LK }\end{array}$ & n & \%age \\
\hline Negative & 21 & 42,0 \\
\hline Positive & 29 & 58,0 \\
\hline Total & 50 & 100,0 \\
\hline
\end{tabular}

Knowledge Relationship with Radiation Protection Behavior for the eyes:

Table 7 Relationship of Respondents' Knowledge with Maintenance and Installation Behavior with the Successful Use of Contact Lenses in 2021 at Metro Optics

\begin{tabular}{|c|c|c|c|c|c|c|c|}
\hline \multirow{3}{*}{ Knowledge } & \multicolumn{4}{|c|}{ Care and Insertion Behavior with Successful Use of Contact Lenses } & \multirow{2}{*}{\multicolumn{2}{|c|}{ Total }} & \multirow{3}{*}{$\begin{array}{c}p- \\
\text { value }\end{array}$} \\
\hline & \multicolumn{2}{|c|}{ Negative } & \multicolumn{2}{|c|}{ Positive } & & & \\
\hline & $\mathbf{N}$ & $\%$ & $\mathbf{N}$ & $\%$ & $\mathbf{N}$ & $\%$ & \\
\hline Negative & 14 & $77,8 \%$ & 4 & $22,2 \%$ & 18 & 100 & \multirow{3}{*}{0,000} \\
\hline Positive & 7 & $21,9 \%$ & 25 & $78,1 \%$ & 32 & 100 & \\
\hline Total & 21 & $42 \%$ & 29 & $58 \%$ & 50 & 100 & \\
\hline
\end{tabular}

Relationship between Attitude and Behavior of Care and Fitting with Successful Use of Contact Lenses:

Table 8 Relationship of Respondents' Attitudes with Care and Installation Behavior with Successful Use of Contact Lenses in 2021.

\begin{tabular}{|c|c|c|c|c|c|c|c|}
\hline \multirow[t]{3}{*}{ Behavioral } & \multicolumn{4}{|c|}{ Attitudes of Care and Installation with Successful Use of Contact Lenses } & \multirow{2}{*}{\multicolumn{2}{|c|}{ Total }} & \multirow{3}{*}{$\begin{array}{c}p- \\
\text { value }\end{array}$} \\
\hline & \multicolumn{2}{|c|}{\begin{tabular}{|c|} 
Negative \\
\end{tabular}} & \multicolumn{2}{|c|}{ Positive } & & & \\
\hline & $\mathbf{N}$ & $\%$ & $\mathbf{n}$ & $\%$ & $\mathbf{N}$ & $\%$ & \\
\hline Negative & 15 & $83,3 \%$ & 3 & $16,7 \%$ & 18 & 100 & \\
\hline Postitive & 6 & $18,8 \%$ & 26 & $81,2 \%$ & 32 & 100 & 0,000 \\
\hline Total & 21 & $42 \%$ & 29 & $58 \%$ & 50 & 100 & \\
\hline
\end{tabular}

\section{DISCUSSION}

The Relationship Between Knowledge and Behavior: The level of knowledge of Care and Installation is related to the Successful Use of Contact Lenses with good knowledge, it is hoped that the Cotemer will carry out Care and Installation with Contact Lenses properly so that it will ensure the success of use. The results of the study indicate that there is a relationship between the respondents' knowledge of Care and Installation and the Successful Use of Contact Lenses.

This indicates that knowledge is a factor that supports respondents in terms of maintenance and installation behavior with successful use of contact lenses. knowledge about maintenance and fitting behavior with successful use of contact lenses is the ability to understand the importance of protection against care and installation with successful 
use of contact lenses behavior based on knowledge will be more lasting than behavior that is not based on knowledge. The Relationship Between Attitude and Behavior: Treatment and installation of contact lenses is a branch of science that studies human and environmental health problems and is related to providing protection to a person or group of people or to their offspring against the possibility of harming health due to the use of contact lenses. The purpose of care and installation of contact lenses is to prevent the occurrence of harmful deterministic effects and reduce the occurrence of stochastic effects to a minimum. With the existence of this branch of science, a group of people who have contact with or use contact lens rehabilitation tools are endeavored to have an appreciation of the safety and security of wearing contact lenses and at the same time have an understanding of the philosophy of individual and environmental health.

In the use of health technology, the human safety factor must get the main priority. Of course, use it as much as possible with minimal risk or eliminate it altogether. Care and installation of contact lenses aims to protect customers as well as service providers and manufacturers, ensuring the health technology used reaches the hands of the public in the right way and is not misused.

The results of the anamnesis contained several questions related to the patient's motivation to use spherical soft contact lenses. The answers given by patients varied greatly. So from the data obtained above, the patient's motivation to use spherical soft contact lenses is the discomfort of wearing glasses when doing activities. The relatively high refractive status coupled with the patient's activities that often exercise such as futsal and basketball, makes the patient feel more comfortable using contact lenses instead of glasses to avoid visual field disturbances. The patient is an astigmatism sufferer who has a high enough motivation to use contact lenses, so this can help smooth the installation and maintenance of toric soft contact lenses that will be used.

In addition to motivation, the important thing to know is the history of the patient's illness and the drugs that are being consumed by the patient. The results of the anamnesis found that the patient had no history of obstructive disease or contraindications to the use of contact lenses. Based on the theoretical study that has been described previously, the medical history of prospective contact lens users determines the success of using contact lenses, at the beginning of use, while using or after using contact lenses. So that patients with a history of contraindications to the use of contact lenses such as diabetes, allergies and a history of surgery are not recommended to use contact lenses.

The results of the patient's anamnesis were not found to use certain drugs. This is important to know because the drugs consumed by the patient are related to the patient's health condition. If you are sick, it is not recommended to use contact lenses until completely healed. Examination of the condition of the outer eyeball includes examination of the eyelids, cornea, conjunctiva and sclera. The results of the examination of the MW brother did not find any abnormalities in all the outer parts of the eyeball. So that the patient fulfills one of the requirements to use contact lenses with normal conditions outside the eyeball.
Measurement of HVID in patients was carried out using a PD meter with the measurement results showing the same value, namely 12.5 in the right and left eyes. This number is a measure of normal HVID in the human cornea. Based on the theoretical basis, HVID measurement serves to determine the diameter of the contact lens that will be used by the patient later.

Soft contact lens care is very important, in this study a questionnaire was filled out by soft contact lens users who often use soft contact lenses. From the overall data obtained, it shows that the respondents have good contact lens care behavior. This test needs to be done so that we can find out how patient contact lens users are in caring for their soft contact lenses. In addition to affecting the history of disease and allergies, how to care for soft contact lenses is able to provide comfort not only the first time they are used. If the treatment is not good, then soft contact lenses are easy to stick with deposits, because contact lens care is related to contact lens hygiene factors before use. The condition of soft contact lenses that are not treated can reduce the life of contact lenses because contact lenses are easily damaged.

\section{CONCLUSION}

Based on gender, as many as 33 male students, while the remaining 17 female students. Some respondents already have good knowledge, attitude, behavior in understanding Contact Lens Care and Installation. There is a relationship between knowledge, attitudes, behavior of respondents with Care and Installation of Contact Lenses with the Successful Use of Contact Lenses in Metro Optics in 2021.

Suggestion: It is better to get used to using the procedure consistently even though you have felt proficient. It is necessary to provide education to increase knowledge and education in the care and installation of contact lenses for all customers.

\section{REFERENCES}

1. Johnson-johnson medical articel. The RealWorld of Toric Contact Lens Wear.the vison care institute Ltd. 2012. 12JULPOS06

2. Emmanuel, O., Dennis, G., 2013. Pattern of Refractive Astigmatism inNigerian High Schools. Nigeria: Sky Journal of Medicine and Medical Sciences. Hal: 3 - 5

3. Saman Wimalasundera. Astigmatism among other Refractive Errors in Children of Southern Sri Lanka. Global Journal of Medical Research: F Diseases. Publisher: Global Journals Inc. (USA) Online ISSN: 2249-4618 \& Print ISSN: 0975-588 Volume 15 Issue 1 Version 1.0 Year 2015

4. Ilyas, S. Kelainan Refraksi dan Kacamata,Edisi kedua, Jakarta: Fakultas Kedokteran UniversitasIndonesia. 2006.

5. Mc Kean CR, Varma R, Cotter SA, et al. Risk Factor for Astigmatism in Preschool Children: The Multiethnic Pediatric Eye Disease and Baltimore, Pediatric Eye Disease Studies. Ophthalmology. 2011; 118(10):1974-1981.

6. Chamberlain P, Morgan PB, Moody KJ, Maldonado-Codina C. Fluctuation in visual acuity during soft toric contact lens wear. Optom Vis Sci. 2011; 88:E534-E538.

7. Flynn LS, Lass JH, Sethi A, Debanne S, Benetz BA, et al. Risk factors for corenal infiltrative events during continuous wear of silicone hydrogel contact lenses. Invest Opthalmol Vis Sci. 2010:51(11):5421-30. 